\title{
Analisis Model Mangsa Pemangsa dengan Adanya Penyakit pada Populasi Mangsa
}

\section{Fardinah}

Program Studi Pendidikan Matematika, FMIPA Universitas Sulawesi Barat

fardinah@unsulbar.ac.id

\begin{abstract}
ABSTRAK
Model mangsa pemangsa adalah model yang digunakan untuk menggambarkan interaksi antara dua populasi yang bersifat mangsa dan pemangsa. Pada model mangsa pemangsa dasar selalu diasumsikan bahwa kedua populasi dalam kondisi sehat. Namun, pada kenyataannya dapat kita jumpai kondisi pada lingkungan yang menunjukkan bahwa terdapat mangsa atau pemangsa dengan kondisi sakit yang berpengaruh terhadap pertahanan hidup dan berburu makanan. Penelitian ini menganalisis model mangsa pemangsa dengan adanya penyakit pada populasi mangsa yaitu dengan menyusun model, menentukan titik kesetimbangan model, serta menganalisis kestabilan lokal titik kesetimbangan model tersebut berdasarkan nilai eigen yang ditentukan dengan kriteria Routh-Hurwitz. Hasil penelitian yang diperoleh yaitu terdapat tiga titik kesetimbangan model yaitu titik kestimbangan tanpa adanya populasi, titik kesetimbangan tanpa populasi mangsa sakit dan titik kesetimbangan tanpa populasi pemangsa. Titik kesetimbangan tanpa adanya populasi tidak stabil dan titik kesetimbangan tanpa adanya populasi mangsa sakit atau pemangsa akan stabil tergantung pada hubungan parameter-parameter yang digunakan dalam model tersebut.
\end{abstract}

Kata Kunci: Model Mangsa Pemangsa, Kestabilan Model, Kriteria Routh-Hurwitz

\begin{abstract}
Predator prey model is a model that used to describe the interaction between two populations that are prey and predator. In the basic predator prey model it is always assumed that both populations are in good health. However, in reality, we can find conditions in the environment which indicate that there are prey or predator with sick conditions that affect survival and hunting for food. This research analyzes a predator prey model with disease in the prey population by formulating a model, determining the equilibrium points of model and analyzing the local stability of equilibrium point based on the eigenvalue determined by Routh-Hurwitz criteria. The results are that there are three equilibrium points, namely equilibrium point without population, equilibrium point without sick prey population and equilibrium point without predator population. Equilibrium point in the absence of population is unstable and Equilibrium point in the absence of sick prey population or predator population will stable depending on the relationship parameters used in the model.
\end{abstract}

Keywords: Predator Prey Model, Stability Of Model, Routh-Hurwitz Criteria

\section{A. PENDAHULUAN}

Interaksi antar individu memiliki beberapa sifat, salah satunya adalah pemangsaan. Pemangsaan merupakan hubungan antara pemangsa dengan mangsa di dalam interaksi dua populasi. Pemangsaan mempunyai pengaruh negatif pada pertumbuhan potensial populasi mangsa, tetapi pada pertumbuhan populasi pemangsa memiliki pengaruh yang positif. 
Seiring dengan perkembangan model matematika realistik dalam ilmu ekologi, matematika sangat baik dalam merefleksikan penggunaannya untuk mendiskripsikan permasalahan pada interaksi populasi dengan model matematika yang salah satunya adalah model mangsa pemangsa. Model ini pertama kali dikemukakan oleh Lotka-Volterra (1926). Model ini menganalisis populasi pemangsa dan mangsa di suatu wilayah dengan mempertimbangkan bahwasanya mangsa adalah sumber makanan satu - satunya penunjang kehidupan pemangsa. Interaksi antara mangsa dan pemangsa akan mempengaruhi perkembangan kedua populasi. Model matematika yang digunakan adalah sistem persamaan diferensial biasa yang menyatakan perubahan jumlah individu pada masing-masing populasi setiap waktunya. Model mangsa pemangsa yang dibentuk oleh Lotka dan Voltera mengasumsikan kedua populasi dalam kondisi sehat. Oleh karena itu tidak ada kendala bagi pemangsa untuk berburu dan bagi mangsa untuk menghindari buruan. Namun, terkadang kondisi di lingkungan menunjukkan adanya populasi yang sakit. Kondisi pemangsa yang sakit akan membuat kemampuan berburu menurun sedangkan bagi mangsa membuat kemampuan menghindar berkurang.

Penelitian mengenai model mangsa pemangsa dengan melibatkan populasi mangsa yang sakit telah dilakukan beberapa peneliti sebelumnya. Hetchcote et.al (2004) meneliti model mangsa pemangsa dengan pertumbuhan logistik dan menggabungkan infeksi dengan pola model SIR (susceptible, infectible, Recovered). Sinha et.al (2010) memodelkan mangsa pemangsa dengan pertumbuhan logistik pada mangsa dan infeksi pada mangsa dipengaruhi oleh lingkungan dengan pola SIS. Wuhaib dan Hasan (2013) meneliti model dengan infeksi pada mangsa yang melibatkan pemanenan. Populasi mangsa yang terinfeksi mampu untuk sembuh dan menjadi populasi sehat yang dapat terinfeksi kembali. Sani et.al (2014) meneliti model penyebaran infeksi pada populasi mangsa dengan pola SIS (susceptible, infectible, susceptible) dan mengkaji kestabilannya dengan metode Next Generation Matrix (NGM). Kumar et.al (2016) meneliti model mangsa pemangsa dengan studi kasus pada penyebaran worm, trojan horse dan antivirus di komputer. Worm yang diasumsikan sebagai pemangsa menginfeksi komputer dengan bantuan interaksi perangkat komputer lainnya yang telah terinfeksi. Sujatha dan Gunasekaran (2016) meneliti model mangsa pemangsa dengan infeksi pola SIS dan mengikutsertakan pemanenan untuk populasi mangsa serta menganalisis kestabilan dengan NGM.

Berdasarkan penjelasan tersebut di atas, pada penelitian ini akan dikaji tentang analisis model mangsa pemangsa dengan adanya penyakit pada populasi mangsa. Diasumsikan bahwa populasi mangsa yang sakit tidak diberikan pengobatan sehingga populasi 
mangsa yang sakit akan mati. Selanjutnya pemangsa yang memangsa mangsa yang sakit akan terinfeksi dan dapat menyebabkan kematian.

Selanjutnya, penelitian ini disusun berdasarkan sistematika berikut ini. Perumusan model diberikan setelah bab ini. Analisis kualitatif kestabilan lokal model di sekitar titik ekuilibrium ditentukan berdasarkan nilai eigen yang ditentukan dengan kriteria Routh-Hurwitz diberikan pada bagian tiga. Simulasi numerik diberikan pada bagian empat. Pada bab lima diberikan kesimpulan dari penelitian ini.

\section{B. METODE}

Penelitian ini berupa analisis kualitatif yang terdiri dari beberapa tahapan sebagai berikut: (1) penentuan asumsi model, dimana tahapan ini adalah tahap menentukan asumsi model. Asumsi diperlukan sebagai batasan sejauh mana model akan dibuat; (2) penurunan model, dimana penurunan model merupakan langkah penyajian hubungan antara mangsa, mangsa sakit dan pemangsa ke dalam model matematika yang berbentuk sistem persamaan diferensial; (3) penentuan titik kesetimbangan; (4) analisis titik kesetimbangan, dimana analisis titik kesetimbangan dilakukan dengan terlebih dahulu melinierisasi sistem di sekitar titik kesetimbangan dengan menentukan matriks Jacobian, selanjutnya menentukan persamaan karakteristik dan selanjutnya menentukan karakteristik nilai eigen menggunakan kriteria Routh-Hurwitz; (5) simulasi model, dimana simulasi model dilakukan menggunakan software Maple 18. Simulasi ini dilakukan untuk mengetahui apakah analisis titik kesetimbangan model sesuai dengan simulasi model; (6) penarikan kesimpulan.

\section{HASIL DAN PEMBAHASAN}

\section{Pemodelan Mangsa Pemangsa dengan Populasi Mangsa Sakit}

Misalkan didefinisikan $x(t)$ adalah populasi mangsa sehat pada suatu habitat pada waktu $t$, $y(t)$ adalah populasi mangsa sakit pada suatu habitat pada waktu $t$ dan $p(t)$ adalah populasi pemangsa pada habitat yang sama dengan populasi mangsa pada waktu t. Hubungan antara mangsa dan pemangsa pada suatu habitat ini diberikan pada Gambar 1.

Asumsi yang digunakan dalam model ini sebagai berikut:

a. Hanya mangsa sehat yang dapat tumbuh. Tanpa adanya pemangsa, mangsa sehat tumbuh secara proporsional sebesar $\alpha$.

b. Infeksi antar mangsa terjadi akibat interaksi, jumlahnya sebanding dengan hasil kali jumlah kedua populasi dengan konstanta $\beta$. Infeksi akan menyebabkan kematian pada populasi mangsa sakit secara proporsional sebesar $\mu$.

c. Mangsa adalah satu-satunya sumber makanan bagi pemangsa sebagai penunjang kehidupan sehingga tidak adanya mangsa akan mengakibatkan kematian pemangsa sebesar $\mu$ sedangkan adanya mangsa mengakibatkan pertumbuhan populasi 
pemangsa sebanding dengan jumlah populasi keduanya sebesar $\alpha_{1}$.

d. Pemangsa yang memangsa mangsa sakit akan mengalami kematian sebanding dengan jumlah kedua populasi dengan konstanta $\alpha_{2}$.

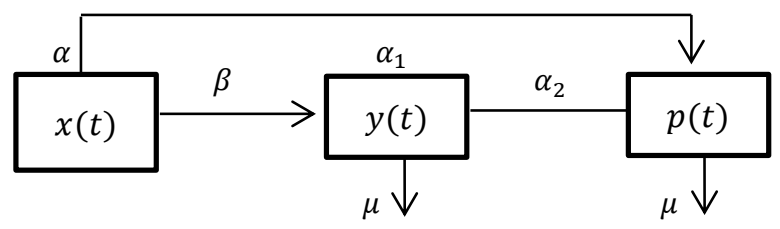

Gambar 1. Kompartemen mangsa dan Pemangsa dalam Model

Berdasarkan asumsi dan diagram kompartemen tersebut, diperoleh model yang menggambarkan perubahan populasi mangsa dan pemangsa dengan adanya penyakit pada populasi mangsa yaitu:

$$
\begin{aligned}
& x=\alpha x-\beta x y-a_{1} x p \\
& y=\beta x y-\alpha_{2} y p-\mu y \\
& p=\alpha_{1} x p-\alpha_{2} y p-\mu p
\end{aligned}
$$

dengan

$x(0) \geq, y(0) \geq, p(0) \geq 0$ dan $\alpha, \beta, \alpha_{1}, \alpha_{2}, \mu \in R^{+}$

\section{Analisis Kestabilan Model}

Berikut diberikan analisis kestabilan model mangsa pemangsa dengan adanya penyakit pada populasi mangsa yang dimulai dengan menentukan titik kesetimbangan model kemudian menganalisis kestabilan lokal setiap titik kesetimbangan tersebut. Titik kesetimbangan sistem (1) diperoleh dari $x^{\prime}=0, y^{\prime}=0$ dan $p^{\prime}=0$. (Verhulst, 1989) Dari sistem persamaan tersebut diperoleh titik kesetimbangan dalam $(x, y, p)$ yaitu:
$E_{1}=(0,0,0), E_{2}=\left(\frac{\mu}{\alpha_{1}}, 0, \frac{\alpha}{\alpha_{1}}\right)$ dan $E_{3}=\left(\frac{\mu}{\beta}, \frac{\alpha}{\beta}, 0\right)$

\section{Preposisi 1}

Titik kesetimbangan $E_{1}=(0,0,0)$ merupakan titik kesetimbangan yang tidak stabil

Bukti:

Matriks Jacobian dari sistem (1) yaitu:

$J=\left(\begin{array}{ccc}\alpha-\beta y-\alpha_{1} p & -\beta x & -\alpha_{1} x \\ \beta y & \beta x-\alpha_{2} p-\mu & -a_{2} y \\ \alpha_{1} p & -a_{2} p & \alpha_{1} x-\alpha_{2} y-\mu\end{array}\right)$

Substitusi $E_{1}=(0,0,0)$ ke matriks Jacobian J diperoleh:

$$
J_{1}=\left(\begin{array}{ccc}
\alpha & 0 & 0 \\
0 & -\mu & 0 \\
0 & 0 & -\mu
\end{array}\right)
$$

Persamaan karakteristik untuk diperoleh $J_{1}$ dari persamaan $\left|J_{1}-\lambda I\right|=0$ (Kocak, 1991), sehingga persamaan karakteristik $J_{1}$ adalah:

$$
(\alpha-\lambda)(-\mu-\lambda)(-\mu-\lambda)=0
$$

Diperoleh nilai eigen dalam bentuk $\left(\lambda_{1}, \lambda_{2}, \lambda_{3}\right)$ yaitu $(\alpha,-\mu,-\mu)$. Karena terdapat nilai eigen positif yaitu $\alpha>0$ maka titik kesetimbangan $E_{1}=(0,0,0)$ tidak stabil (Olsder, 1994)

\section{Preposisi 2}

Titik kesetimbangan $\quad E_{2}=\left(\frac{\mu}{\alpha_{1}}, 0, \frac{\alpha}{\alpha_{1}}\right)$ merupakan titik kesetimbangan yang stabil dengan syarat $\frac{\beta}{\alpha \alpha_{1}}<\frac{\alpha \alpha_{2}}{\beta-\alpha_{1}}$ dan $\beta>\alpha_{1}$

Bukti:

Matriks Jacobian untuk $E_{2}=\left(\frac{\mu}{\alpha_{1}}, 0, \frac{\alpha}{\alpha_{1}}\right)$ adalah:

$$
J_{2}=\left(\begin{array}{ccc}
0 & -\frac{\beta}{\mu} & -\mu \\
0 & \frac{\beta \mu-\alpha \alpha_{2}-\mu \alpha_{1}}{\alpha_{1}} & 0 \\
\alpha & -\frac{\alpha \alpha_{2}}{\alpha_{1}} & 0
\end{array}\right)
$$


Persamaan karakteristik untuk $J_{2}$ diperoleh dari persamaan $\left|J_{2}-\lambda I\right|=0$ sehingga persamaan karakteristik matriks $J_{2}$ adalah:

$$
\begin{aligned}
& \lambda^{3}-\left(\beta \mu-\alpha \alpha_{2}-\mu \alpha_{1}\right) \lambda^{2}+\alpha \mu \lambda \\
& -\alpha \mu\left(\beta \mu-\alpha \alpha_{2}-\mu \alpha_{1}\right)=0
\end{aligned}
$$

Berdasarkan kriteria Routh-Hurwitz diperoleh bahwa persamaan karakteristik matriks $J_{2}$ akan menghasilkan akar-akar atau nilai eigen yang lebih kecil atau sama dengan nol dengan syarat $\beta \mu-\alpha \alpha_{2}-\mu \alpha_{1}<0$ dan $\frac{\alpha \alpha_{1} \mu}{\beta}=1$. Dari syarat tersebut diperoleh $\frac{\beta}{\alpha \alpha_{1}}<\frac{\alpha \alpha_{2}}{\beta-\alpha_{1}} \operatorname{dan} \beta>\alpha_{1}$

Dengan demikian titik kesetimbangan $E_{2}=\left(\frac{\mu}{\alpha_{1}}, 0, \frac{\alpha}{\alpha_{1}}\right)$ stabil jika $\frac{\beta}{\alpha \alpha_{1}}<\frac{\alpha \alpha_{2}}{\beta-\alpha_{1}}$ dan $\beta>\alpha_{1}$

\section{Preposisi 3}

Titik kesetimbangan $c$ merupakan titik kesetimbangan yang stabil dengan syarat $\frac{\beta}{\alpha \alpha_{1}}<\frac{\alpha \alpha_{2}}{\beta-\alpha_{1}} \operatorname{dan} \beta>\alpha_{1}$.

Bukti:

Matriks Jacobian untuk $E_{3}=\left(\frac{\mu}{\beta}, \frac{\alpha}{\beta}, 0\right)$ adalah:

$$
J_{3}=\left(\begin{array}{ccc}
0 & -\mu & -\frac{\alpha_{1} \mu}{\beta} \\
\alpha & 0 & -\frac{\alpha \alpha_{2}}{\beta} \\
0 & 0 & \frac{\alpha_{1} \mu-\alpha \alpha_{2}-\mu \beta}{\beta}
\end{array}\right)
$$

Persamaan karakteristik untuk ${ }^{J_{3}}$ diperoleh dari persamaan $\left|J_{3}-\lambda I\right|=0$, sehingga persamaan karakteristik matriks ${ }{ }_{3}$ adalah:

$$
\lambda^{3}-\left(\frac{\alpha_{1} \mu-\alpha \alpha_{2}-\mu \beta}{\beta}\right) \lambda^{2}+\frac{\alpha \alpha_{1} \mu}{\beta} \lambda
$$

$$
-\frac{\alpha \mu\left(\alpha_{1} \mu-\alpha \alpha_{2}-\mu \beta\right.}{\beta^{2}}=0
$$

Berdasarkan kriteria Routh-Hurwitz diperoleh bahwa persamaan karakteristik matriks $J_{3}$ akan menghasilkan akar-akar atau nilai eigen yang lebih kecil atau sama dengan nol dengan syarat $\beta \mu-\alpha \alpha_{2}-\mu \alpha_{1}<0$ dan $\frac{\alpha \alpha_{1} \mu}{\beta}=1$. Dari syarat tersebut diperoleh $\frac{\beta}{\alpha \alpha_{1}}<\frac{\alpha \alpha_{2}}{\alpha_{1}-\beta}$ dan $\alpha_{1}>\beta$

Dengan demikian titik kesetimbangan $E_{3}=\left(\frac{\mu}{\beta}, \frac{\alpha}{\beta}, 0\right)$ stabil jika $\frac{\beta}{\alpha \alpha_{1}}<\frac{\alpha \alpha_{2}}{\alpha_{1}-\beta}$ dan $\alpha_{1}>\beta$

\section{Simulasi}

Pada bagian ini akan dilakukan simulasi dengan mengambil nilai parameter yang digunakan dalam model yang terdiri dari dua jenis parameter seperti disajikan dalam Tabel 1 berikut.

Tabel 1. Parameter simulasi model

\begin{tabular}{ccc}
\hline Parameter & E1 dan E2 & E3 \\
\hline$\alpha$ & 4 & 4 \\
\hline$\alpha_{1}$ & 3 & 1 \\
\hline$\alpha_{2}$ & 3 & 3 \\
\hline$\beta$ & 1 & 2 \\
\hline$\mu$ & 1 & 1 \\
\hline
\end{tabular}

Berikut diberikan ruang fase hasil simulasi titik kesetimbangan E1 dengan nilai awal $(x(0), y(0), p(0))=(0.03,0.01,0.01)$. 


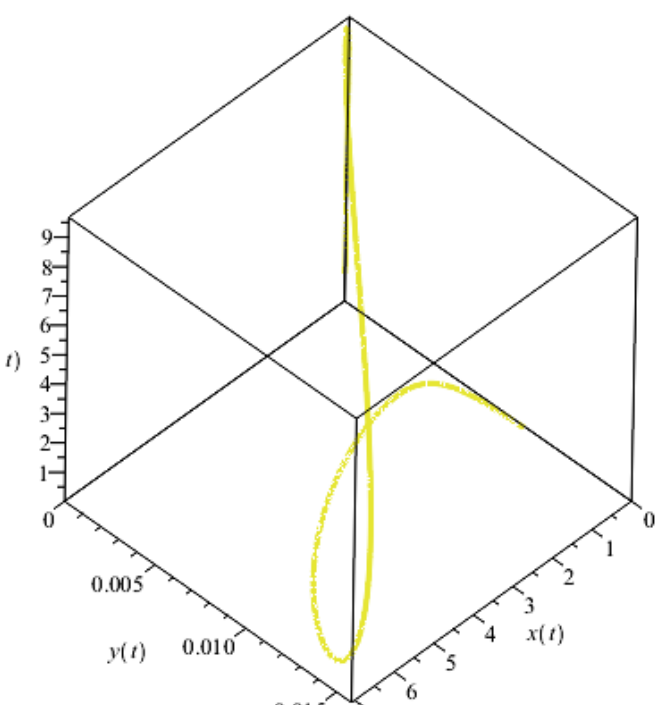

Gambar 2. Ruang fase model sistem (1) dengan menggunakan parameter pada Tabel 1

Pada gambar tersebut, terlihat bahwa kurva bergerak menjauhi titik kesetimbangan E1 sepanjang waktu t. Hal ini sesuai dengan hasil analisis titik kesetimbangan E1 yang diperoleh bahwa titik kesetimbangan E1 tidak stabil.

Berikut diberikan ruang fase hasil simulasi titik kesetimbangan E2 dengan nilai awal $(x(0), y(0), p(0))=(1.01,0.01,4.01)$.

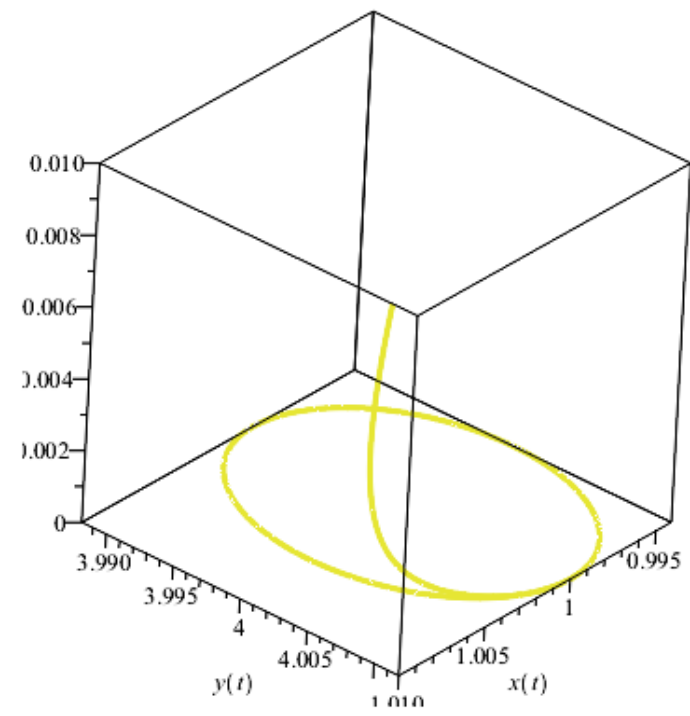

Gambar 3. Ruang fase model sistem (1) dengan menggunakan parameter pada Tabel 1
Pada gambar tersebut, terlihat bahwa kurva bergerak dari nilai awal kemudian menuju ke titik kesetimbangan E2. Namun sepanjang waktu t, kurva tersebut hanya bergerak mengelilingi titik kesetimbangan E2 dan tidak pernah mendekati atau menuju ke E2.

Hal ini sesuai dengan hasil analisis titik kesetimbangan E2 yang diperoleh bahwa titik kesetimbangan E2 stabil asalkan terpenuhi syarat kestabilan yaitu $\beta<\alpha^{2} \alpha_{2}+\alpha_{1}$

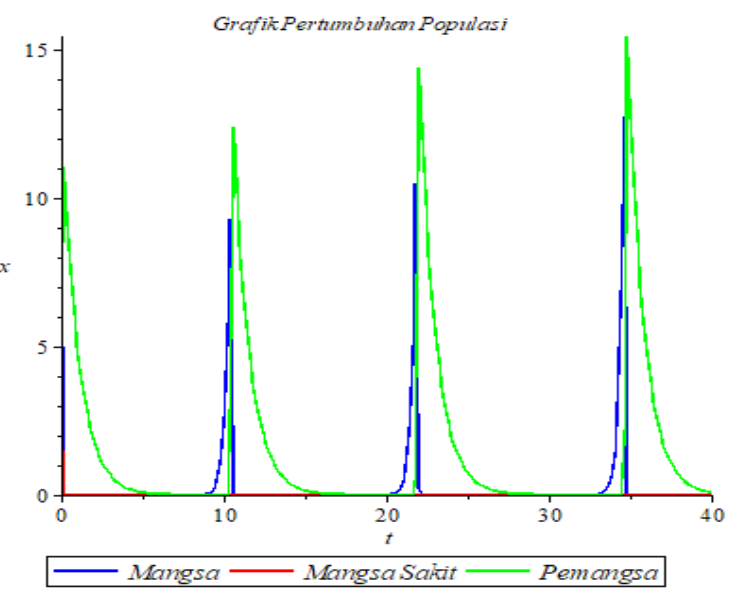

Gambar 4. Grafik pertumbuhan populasi berdasarkan E2

Dari gambar tersebut dapat dilihat bahwa ketika laju pemangsaan lebih besar dari pada laju infeksi maka seiring berjalannya waktu, populasi mangsa terus berkurang namun tidak sampai mengalami kepunahan dan populasi pemangsa terus bertambah sedangkan populasi mangsa sakit akan mengalami kepunahan.

Berikut diberikan ruang fase hasil simulasi titik kesetimbangan E3 dengan nilai awal $(x(0), y(0), p(0))=(10,3,6)$. 


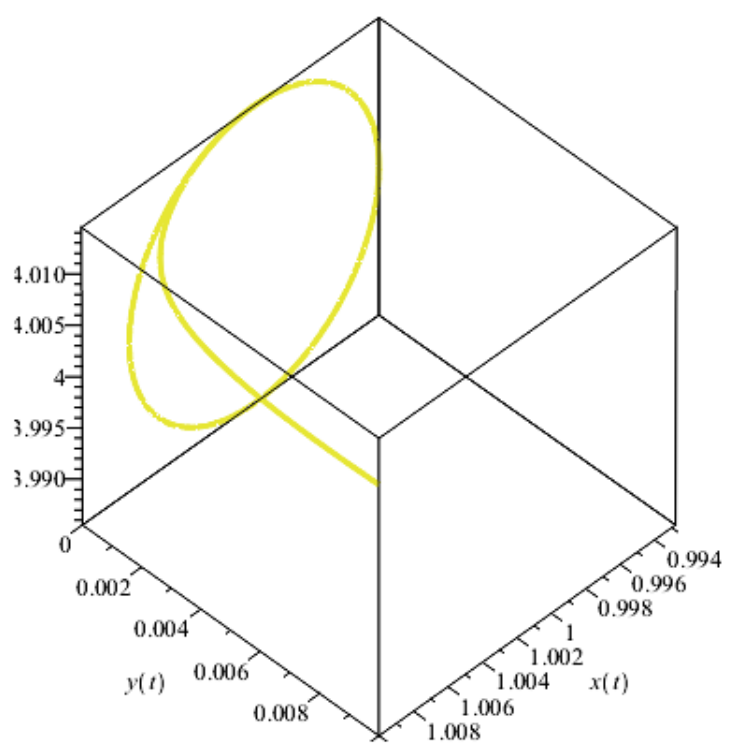

Gambar 5. Ruang fase model sistem (1) dengan menggunakan parameter pada Tabel 1

Pada gambar tersebut, terlihat bahwa kurva bergerak dari nilai awal kemudian menuju ke titik kesetimbangan E3. Namun sepanjang waktu $t$, kurva tersebut hanya bergerak mengelilingi titik kesetimbangan E3 dan tidak pernah mendekati atau menuju ke E2. Hal ini sesuai dengan hasil analisis titik kesetimbangan E3 yang diperoleh bahwa titik kesetimbangan E3 stabil asalkan terpenuhi syarat kestabilan yaitu $\alpha_{1}<\alpha^{2} \alpha_{2}+\beta$

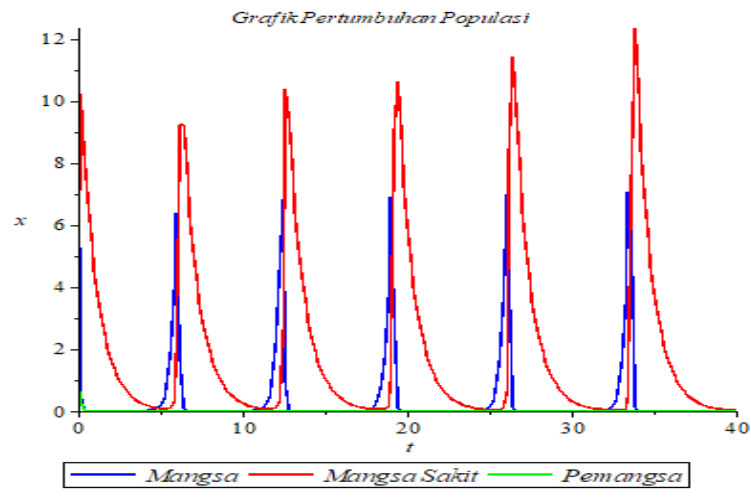

Gambar 6. Grafik pertumbuhan populasi berdasarkan E3
Dari gambar tersebut dapat dilihat bahwa ketika laju infeksi lebih besar dari pada laju pemangsaan maka seiring berjalannya waktu, jumlah populasi mangsa sakit terus mengalami pertambahan seiring bertambahnya jumlah populasi mangsa sehat. Sedangkan jumlah populasi pemangsa semakin berkurang karena berkurangnya sumber makanan (mangsa sehat) sehingga seiring berjalannya waktu populasi pemangsa akan punah.

\section{PENUTUP}

\section{Kesimpulan}

Berdasarkan penelitian yang telah dilakukan, dapat disimpulkan bahwa:

a) Model mangsa pemangsa dengan populasi mangsa sakit yaitu:

$$
\begin{aligned}
& x=\alpha x-\beta x y-a_{1} x p \\
& y=\beta x y-\alpha_{2} y p-\mu y \\
& p=\alpha_{1} x p-\alpha_{2} y p-\mu p
\end{aligned}
$$

$x(0) \geq, y(0) \geq, p(0) \geq 0$

$\operatorname{dan} \alpha, \beta, \alpha_{1}, \alpha_{2}, \mu \in R^{+}$

b) Terdapat 3 (tiga) titik kesetimbangan model yaitu:

$$
\begin{aligned}
& E_{1}=(0,0,0), E_{2}=\left(\frac{\mu}{\alpha_{1}}, 0, \frac{\alpha}{\alpha_{1}}\right) \text { dan } \\
& E_{3}=\left(\frac{\mu}{\beta}, \frac{\alpha}{\beta}, 0\right)
\end{aligned}
$$

c) Titik kesetimbangan E1 tidak stabil, titik kesetimbangan E2 stabil dengan syarat $\frac{\beta}{\alpha \alpha_{1}}<\frac{\alpha \alpha_{2}}{\beta-\alpha_{1}} \quad$ dan $\quad \beta>\alpha_{1} \quad$ dan titik kesetimbangan E3 stabil dengan syarat $\frac{\beta}{\alpha \alpha_{1}}<\frac{\alpha \alpha_{2}}{\alpha_{1}-\beta}$ dan $\alpha_{1}>\beta$

d) Ketika laju pemangsaan lebih besar dari pada laju infeksi maka seiring berjalannya 
waktu populasi mangsa sakit akan mengalami kepunahan.

e) Ketika laju infeksi lebih besar dari pada laju pemangsaan maka seiring berjalannya waktu populasi pemangsa akan mengalami kepunahan.

\section{Saran}

Berdasarkan hasil penelitian yang telah diperoleh, peneliti dapat memberikan saran yaitu agar penelitian selanjutnya lebih dikembangkan lagi dengan mengikutsertakan faktor lain selain faktor yang terdapat dalam penelitian ini seperti adanya pengobatan atau konservasi pada populasi mangsa yang sakit atau dengan menambahkan asumsi-asumsi lain.

\section{DAFTAR PUSTAKA}

Hethcote, H.W., Wang,W., Han,L., Zhien Ma. (2004). A predator-prey model with infected prey, Theoretical Population Biology 66, $259-268$.

Kocak, H. dan Hale, J.K. (1991). Dynamic and Bifurcation. New York: Springer Verlag.

Kumar, M., Bimal Kumar Mishra \& T. C. Panda. (2016). Predator-Prey Models on Interaction between Computer Worms,
Trojan Horse and Antivirus Software Inside a Computer System, International Journal of Security and Its Applications, Vol. 10, No. 1, 173-190.

Olsder, G.J. (1994). Mathematical Systems Theory. Netherlands: Delftse Uitgevers Maatschappij, CW Delft.

S.A. Wuhaib, Y. Abu Hasan. (2013). A predator infected prey model with harvesting of infected Prey, ScienceAsia 39S, 37-41.

Sani,A., Cahyono,E., Mukhsar, G.A., Rahman, Y.T. Hewindati, F.A.A. Faeldog, F.A. Abdullah. (2014). Dynamics of Disease Spread in a Predator-Prey System, Advanced Studies in Biology, vol. 6, No. 4, $169-179$.

Sinha,S., Misra,O.P., Dhar, J. (2010). Modelling a predator-prey system with infected prey in polluted environment, Applied Mathematical Modelling, 34, 1861-1872.

Sujatha, K., Gunasekaran, M. (2016). Dynamics in a Harvested Prey-Predator Model with Susceptible-Infected-Susceptible Epidemic Disease in the Prey, Advances in Applied Mathematical Biosciences. ISSN 2248-9983 Volume 7, No. 1, 23-31.

Verhulst, F. (1990). Nonlinear Differential Equations and Dynamical Systems. NewYork, USA: Springer - Verlag. 